\title{
Comparison of Convenience Sampling and Purposive Sampling
}

\author{
Ilker Etikan, Sulaiman Abubakar Musa, Rukayya Sunusi Alkassim \\ Department of Biostatistics, Near East University, Nicosia-TRNC, Cyprus \\ Email address: \\ ietikan@gmail.com (I. Etikan), ietikan@hotmail.com (I. Etikan), sulebah002@gmail.com (S. A. Musa), \\ rukayyaalkassim@gmail.com (R. S. Alkassim)
}

\section{To cite this article:}

Ilker Etikan, Sulaiman Abubakar Musa, Rukayya Sunusi Alkassim. Comparison of Convenience Sampling and Purposive Sampling. American Journal of Theoretical and Applied Statistics. Vol. 5, No. 1, 2016, pp. 1-4. doi: 10.11648/j.ajtas.20160501.11

\begin{abstract}
This article studied and compared the two nonprobability sampling techniques namely, Convenience Sampling and Purposive Sampling. Convenience Sampling and Purposive Sampling are Nonprobability Sampling Techniques that a researcher uses to choose a sample of subjects/units from a population. Although, Nonprobability sampling has a lot of limitations due to the subjective nature in choosing the sample and thus it is not good representative of the population, but it is useful especially when randomization is impossible like when the population is very large. It can be useful when the researcher has limited resources, time and workforce. It can also be used when the research does not aim to generate results that will be used to create generalizations pertaining to the entire population. Therefore, there is a need to use nonprobability sampling techniques. The aim of this study is to compare among the two nonrandom sampling techniques in order to know whether one technique is better or useful than the other. Different articles were reviewed to compare between Convenience Sampling and Purposive Sampling and it is concluded that the choice of the techniques (Convenience Sampling and Purposive Sampling) depends on the nature and type of the research.
\end{abstract}

Keywords: Convenience Sampling, Purposive Sampling, Sampling Techniques

\section{Introduction}

Sample is a portion of a population or universe [20]. However, by population, many often consider to people only. Population does not necessarily mean a number of people [22]. It can also refer to total quantity of the things or cases which are the subject of our research. Probability sampling is defined as having the "distinguishing characteristic that each unit in the population has a known, nonzero chance of being included in the sample" [8]. It is described more clearly as "every participant has an equal probability of being selected" from the population [6]. In probability sampling, each element in the population has a known nonzero chance of being selected through the use of a random selection procedure [1]. In nonprobability sampling, randomization is not important in selecting a sample from the population of interest. Rather, subjective methods are used to decide which elements are included in the sample. Hence, nonprobability sampling is a sampling technique where the samples are gathered in a process that does not give all the participants or units in the population equal chances of being included.
Why would researcher consider using nonprobability sampling? In some situations, the population may not be well defined. In other situations, there may not be great concern in drawing inferences from the sample to the population. Perhaps, the most common reason for using nonprobability sampling is that it is cheaper than probability sampling and can often be implemented more quickly [1].

It is very crucial for a researcher to determine which non probability sampling technique is applicable to his study. The technique to be used depends on the type, nature and purpose of the study. When subjects are chose because of the close proximity to a researcher, that is, the ones that are easier for the researcher to access, the researcher is making a convenience sampling. But for purposive sampling, a researcher has something in mind and participants that suit the purpose of the study are included.

\section{Convenience Sampling}

In every type of research, it would be superlative to use the whole population, but in most cases, it is not possible to 
include every subject because the population is almost finite. This is the rationale behind using sampling techniques like convenience sampling by most researchers [5].

Convenience sampling (also known as Haphazard Sampling or Accidental Sampling) is a type of nonprobability or nonrandom sampling where members of the target population that meet certain practical criteria, such as easy accessibility, geographical proximity, availability at a given time, or the willingness to participate are included for the purpose of the study [4]. It is also referred to the researching subjects of the population that are easily accessible to the researcher [18]. Convenience samples are sometimes regarded as 'accidental samples' because elements may be selected in the sample simply as they just happen to be situated, spatially or administratively, near to where the researcher is conducting the data collection. Ecological data are often taken using convenience sampling, here data are collected along roads, trails or utility corridors and hence are not representative of population of interest. Other example of convenience sampling include data taken subjectively near camp, around parking areas, or an areas where density is known to be high. Biologist often use convenience sampling in the field work because it is easier like walking on a road and stop occasionally to record numbers. With numbers derive from convenience sampling, one can make only weak statement about some characteristic of the sample itself rather than a formal inductive inference concerning the population of interest. Further explains that, "captive participants such as students in the researcher's own institution are main examples of convenience sampling" [4].

Convenience Sampling is affordable, easy and the subjects are readily available. It is compulsory for the researcher to describe how the sample would differ from the one that was randomly selected. It is also necessary to describe the subjects who might be excluded during the selection process or the subjects who are overrepresented in the sample [5]. The main objective of convenience sampling is to collect information from participants who are easily accessible to the researcher like recruiting providers attending a staff meeting for study participation. Although commonly used, it is neither purposeful nor strategic [11]. The main assumption associated with convenience sampling is that the members of the target population are homogeneous. That is, that there would be no difference in the research results obtained from a random sample, a nearby sample, a co-operative sample, or a sample gathered in some inaccessible part of the population [10].

Point out that the obvious disadvantage of convenience sampling is that it is likely to be biased [13]. They advise researchers that the convenience sampling should not be taken to be representative of the population. Still, there is another problem of great concern related to convenience sampling, i.e. the problem of outliers. Because of the high self-selection possibility in non-probability sampling, the effect of outliers can be more devastating in this kind of subject selection. Outliers are cases whom consider as not belonging to the data. In a convenience sample, on the contrary, neither biases nor their probabilities are quantified [7]. In fact, the researcher does not know how well a convenience sample will represent the population regarding the traits or mechanism under research. What makes convenience samples so unpredictable is their vulnerability to severe hidden biases [12].

\subsection{Benchmark Problem}

A psychologist is interested in the impacts of social network on study habits of Nigerian university students. To test the whole population, the researcher would need all current university students and hence, a lot of time, energy and resources.

A sample would be a selection of few students from all of the Universities in Nigeria, which the researcher has to get for the testing.

The convenience sample here would be a group of students from Abubakar Tafawa Balewa University, Bauchi, a Nigerian University where the Psychologist is working as lecturer.

We learnt from the above that, the psychologist was subjective as the only students of Abubakar Tafawa Balewa University, Bauchi were included in the study. With this sample the researcher would utilize little time and resource. The selected students in this study are different from other Nigerian University students. Thus, this may undermine the ability of the Psychologist to make generalisations from the sample to the population.

Therefore, in convenience sampling, the individuals selected by the researcher may not be applicable to the research problem. Hence, there is a risk of collecting poor quality data due to poor research outcomes and as such, difficult to convince others to accept the findings of research based on poor foundation [16]. Some methods literature disregards convenience sampling as being an inappropriate method in social research due to the severe limitations [12].

\subsection{Purposive Sampling}

Data gathering is crucial in research, as the data is meant to contribute to a better understanding of a theoretical framework [2]. It then becomes imperious that selecting the manner of obtaining data and from whom the data will be acquired be done with sound judgment, especially since no amount of analysis can make up for improperly collected data [21]. The purposive sampling technique, also called judgment sampling, is the deliberate choice of a participant due to the qualities the participant possesses. It is a nonrandom technique that does not need underlying theories or a set number of participants. Simply put, the researcher decides what needs to be known and sets out to find people who can and are willing to provide the information by virtue of knowledge or experience [2]. It is typically used in qualitative research to identify and select the information-rich cases for the most proper utilization of available resources [17]. This involves identification and selection of individuals or groups of individuals that are proficient and well-informed with a phenomenon of interest [3]. In addition to knowledge and experience, [2] and [19] note the importance of availability and willingness to participate, and the ability to communicate experiences and opinions in an articulate, expressive, and reflective manner. Unlike random 
studies, which deliberately include a diverse cross section of ages, backgrounds and cultures, the idea behind purposive sampling is to concentrate on people with particular characteristics who will better be able to assist with the relevant research.

\section{Purposive Sampling Methods}

\subsection{Maximum Variation Sampling}

The idea behind MVS is to look at a subject from all available angles, thereby achieving a greater understanding. Also known as "Heterogeneous Sampling", it involves selecting candidates across a broad spectrum relating to the topic of study. For example, if one was researching an education program would include students who hated the program, students classed as "typical" and students who excelled. This type of sampling is useful when a random sample is not taken, for instance, if the sample pool is too small.

\subsection{Homogeneous Sampling}

This form of sampling, unlike MVS, focuses on candidates who share similar traits or specific characteristics. For example, participants in Homogenous Sampling would be similar in terms of ages, cultures, jobs or life experiences. The idea is to focus on this precise similarity and how it relates to the topic being researched. For example, if one was researching long-term side effects of working with asbestos, for a Homogenous Sampling, the only people who had worked with asbestos for 20 years or longer are included.

\subsection{Typical Case Sampling}

TCS is useful when a researcher is dealing with large programs, it helps set the bar of what is standard or "typical". Candidates are generally chosen based on their likelihood of behaving like everyone else. For example, if one was researching the reactions of $9^{\text {th }}$ grade students to a job placement program, would select classes from similar socioeconomic regions, as opposed to selecting a class from an a poorer inner city school, another from a mid-west farming community, and another from an affluent private school.

\subsection{Extreme/Deviant Case Sampling}

The polar opposite of Typical Case Sampling, Extreme (or Deviant) Case Sampling is designed to focus on individuals that are unusual or atypical. This form of sampling is more often used when researchers are developing "best in practice" guidelines or are looking into "what not to do". An example would be a study into heart surgery patients who recovered significantly faster or slower than average. Researchers would be looking for variations in these cases to explain why their recoveries were atypical.

\subsection{Critical Case Sampling}

Extremely popular in the initial stages of research to determine whether or not a more in depth study is warranted, or where funds are limited, Critical Case Sampling is a method where a select number of important or "critical" cases are selected and then examined. The criterion for deciding whether or not an example is "critical" is generally decided using the following statements: "If it happens there, will it happen anywhere?" or "if that group is having problems, then can we be sure all the groups are having problems?"

\subsection{Total Population Sampling}

On occasion, it may be that leaving out certain cases from your sampling would be as if you had an incomplete puzzle with obvious pieces missing. In this instance, the best sampling method to use is Total Population Sampling. TPS is a technique where the entire population that meet the criteria (e.g. specific skill set, experience, etc.) are included in the research being conducted. Total Population Sampling is more commonly used where the number of cases being investigated is relatively small.

\subsection{Expert Sampling}

As indicated by the name, Expert Sampling calls for experts in a particular field to be the subjects of the purposive sampling. This sort of sampling is useful when the research is expected to take a long time before it provides conclusive results or where there is currently a lack of observational evidence. Expert sampling is a positive tool to use when investigating new areas of research, to garner whether or not further study would be worth the effort.

\section{Benchmark Problem}

A data analyst wants to get an opinion from pregnant women who attend second Ante Natal Care (ANC2 or $2^{\text {nd }}$ ANC) pertaining their pregnancy in Kano State of Nigeria for the month of October, 2015. The analyst goes to the health facilities offering Ante Natal Care service and then focus on pregnant women that come for Second ANC (ANC2).

Here, the analyst's target is pregnant women who come for second ANC and those who come for first, third and 4 or more ANCs are excluded. That is the purposive sampling because it starts with a purpose in mind and the sample is thus selected to include people of interest and exclude those who do not suit the purpose.

\section{Convenience Sampling Versus Purposive Sampling}

Convenience sampling technique is applicable to both qualitative and quantitative studies, although it is most frequently used in quantitative studies while purposive sampling is typically used in qualitative studies [5]. Quantitative methods are intended to achieve breadth of understanding while qualitative methods are for the most part, intended to achieve depth of understanding [17]. Observe, whether the technique employed is convenience sampling or 
purposive sampling, validity and efficiency are of utmost important [15]. However, sampling must be consistent with the assumptions and objectives essential in the use of either convenience sampling or purposive sampling. Purposive sampling methods place primary emphasis on saturation (i.e., obtaining a comprehensive understanding by continuing to sample until no new substantive information is acquired) [14]. Convenience sampling methods place primary emphasis on generalizability (i.e., ensuring that the knowledge gained is representative of the population from which the sample was drawn). Each methodology, in turn, has different expectations and standards for determining the number of participants required to achieve its aims. In convenience sampling, researcher selects subjects that are more readily accessible, Thus, opportunity to participate is not equal for all qualified individuals in the target population and study results are not necessarily generalizable to the population, while in purposive Sampling, subjects are selected based on study purpose with the expectation that each participant will provide unique and rich information of value to the study. As sample size increase the statistical power of the convenience sample also increases while in purposive sampling, Sample size is determined by data saturation not by statistical power analysis [23].

\section{Conclusion}

The above comparison shows that, both convenience sampling and purposive sampling share some limitations which include nonrandom selection of participants, that is to say the researcher is subjective and bias in choosing the subjects of the study. This impedes the researcher's ability to draw inferences about a population. The study also shows that although, convenience sampling can be used in both qualitative and quantitative study, but it is frequently used in quantitative study while purposive sampling is typically used in qualitative study. Purposive sampling technique cannot be used when the variables in the study are quantitative in nature and also in convenience sampling, the nature of the research is mostly quantitative. Thus, the choice of technique to be used depends on the type and nature of the study.

\section{References}

[1] Battaglia, M. P. (2008). Non Probability Sampling . Encyclopedia of Survey Resesrch Methods. 2008. SAGE Publications, 1-4.

[2] Bernard, H. R. (2002). Research methods in anthropology: Qualitative and quantitative approaches (3rd ed.). Walnut Creek, CA: Alta Mira Press.

[3] Cresswell, J. W., \& Plano Clark, V. L. (2011). Designing and Conducting mixed method research (2nd ed.). Thousand Oaks, CA: Sage.
[4] Dörnyei, Z. (2007). Research methods in applied linguistics. New York: Oxford University Press.

[5] Explorable.com. (2009, Sep 16). Convenience Sampling. Retrieved Nov 13, 2015, from https://explorable.com/convenience-sampling

[6] Fink, Arlene. How to Sample in Surveys. Vol. 6. London: Sage Publications, 1995.

[7] Hatch, E. \& Lazaraton, A. (1991). The research manual: Design and statistics for applied linguistics. New York: Newbury House Publishers.

[8] Henry, Gary T. Practical Sampling. Vol. 21. London: Sage Publications, 1990.

[9] http://dissertation.laerd.com/purposive-sampling.php\#types.

[10] http://www.unesco.org/iiep.

[11] Lawrence A Palinkas, Carla A Green, Jennifer P Wisdom, \& Kimberly Eaton Hoagwood. (2013). Purposeful Sampling for Qualitative Data Collection and Analysis in Mixed Method Implementation Research. Reearch Gate.

[12] Leiner, D. J. (2014). Convenience Samples and Respondent Pools. 1-36.

[13] Mackey, A. \& Gass, S. (2005). Second language research: Methodology and design. New Jersey: Lawrence Erlbaum Associates, Inc.

[14] Miles, M. B., \& Huberman, A. M. (1994). Qualitative data analysis: An expanded sourcebook (2nd ed.). Thousand Oaks, CA: Sage.

[15] Morse, J. M., \& Niehaus, L. (2009). Mixed method design: Principles and procedures. Walnut Creek, CA: Left Coast Press.

[16] Oppong, S. H. (2013). The problem of sampling in qualitative research. Asian journal of management sciences and education, $1-9$.

[17] Patton, M. Q. (2002). Qualitative research and evaluation methods 3rd ed. Thousand Oaks, CA: Sage.

[18] S. K., \& Given Lisa M. (2008). Convenience Sample. In The SAGE Encyclopedia of Qualitative Research Methods. Thousand Oaks, CA: Sage.

[19] Spradley, J. P. (1979). The ethnographic interview. New York: Holt, Rinehart \& Winston.

[20] Tailor, G. R. (Ed.). (2005). Integrating quantitative and qualitative methods in research. Maryland: University Press of America Inc.

[21] Tongco, M. D. (nd). Purposive Sampling as a Tool for Informant Selection. A Journal of Plant, People and Applied Research Ethnobotany Research and Applications, 1-12.

[22] Walliman, N. (2011). Research methods: The basics. New York: Rout ledge.

[23] Zhi., H. L. (2014). A comparison of convenience sampling and purposive sampling. PubMed, 105-11. 